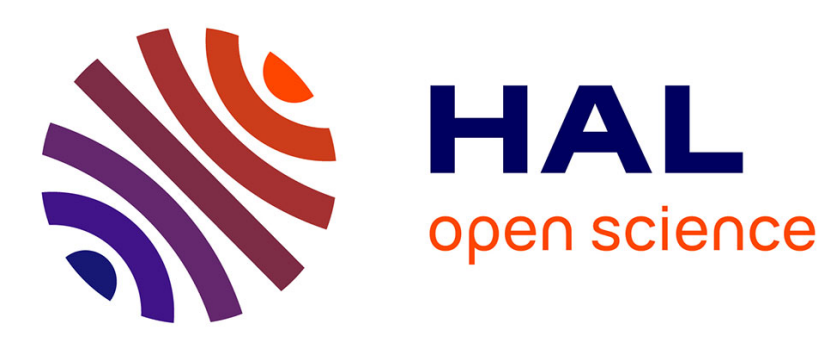

\title{
An inflatable fabric beam finite element
}

Christian Wielgosz, Jean-Christophe Thomas

\section{To cite this version:}

Christian Wielgosz, Jean-Christophe Thomas. An inflatable fabric beam finite element. Communications in Numerical in Engineering, 2003, 19 (4), pp.307-312. 10.1002/cnm.592 . hal-01005236

\section{HAL Id: hal-01005236 \\ https://hal.science/hal-01005236}

Submitted on 3 Dec 2016

HAL is a multi-disciplinary open access archive for the deposit and dissemination of scientific research documents, whether they are published or not. The documents may come from teaching and research institutions in France or abroad, or from public or private research centers.
L'archive ouverte pluridisciplinaire HAL, est destinée au dépôt et à la diffusion de documents scientifiques de niveau recherche, publiés ou non, émanant des établissements d'enseignement et de recherche français ou étrangers, des laboratoires publics ou privés. 


\title{
An inflatable fabric beam finite element
}

\author{
C. Wielgosz and J. C. Thomas \\ Laboratoire de Génie Civil de Nantes, Saint Nazaire, Faculté des Sciences et des Techniques, \\ Université de Nantes, 2, rue de la Houssinière, BP 92206, 44322 Nantes Cedex 03, France
}

Inflatable structures made of modern textile materials with important mechanical characteristics can be inflated at high pressure (up to several hundreds $\mathrm{kPa}$ ). For such values of the pressure they have a strong mechanical strength. The aim of the paper is to construct a new inflatable beam finite element able to predict the behaviour of inflatable structures made of beam elements. Experiments and analytical studies on inflatable fabric beams at high pressure have shown that their compliance is the sum of the beam compliance and of the yarn compliance. This new finite element is therefore obtained by the equilibrium finite element method and is modified into a displacement finite element. The stiffness matrix takes into account the inflation pressure. Comparisons between experimental and numerical results are shown and prove the accuracy of this new finite element for solving problems of inflatable beams at high pressure.

KEY WORDS: inflatable beams; high pressure; following forces

\section{INTRODUCTION}

This paper presents results from research on the mechanics of inflatable beams at high pressure. Such structures have many interesting properties: they are light, easily folding and present reversible behaviour after failure. Inflation gives tension prestressing in the fabrics and imply an important mechanical strength when the pressure reaches several hundreds $\mathrm{kPa}$. A high pressure is interesting because their limit load is proportional to the applied pressure and their deflections are inversely proportional to the constitutive law of the fabrics and to the applied pressure [1]. Analytical developments have been done to calculate wrinkling loads and deflections of cantilever beams [2,3]. The pressure used in Reference [3] was less than $70 \mathrm{kPa}$. We have studied the case of simply supported beams [1] for values of the pressure going up to $300 \mathrm{kPa}$. The results on the wrinkling or collapse load are directly connected to the applied pressure and independent on the materials characteristics. Analytical results on the deflections are only relative to isostatic inflatable beams. The aim of this paper is to 


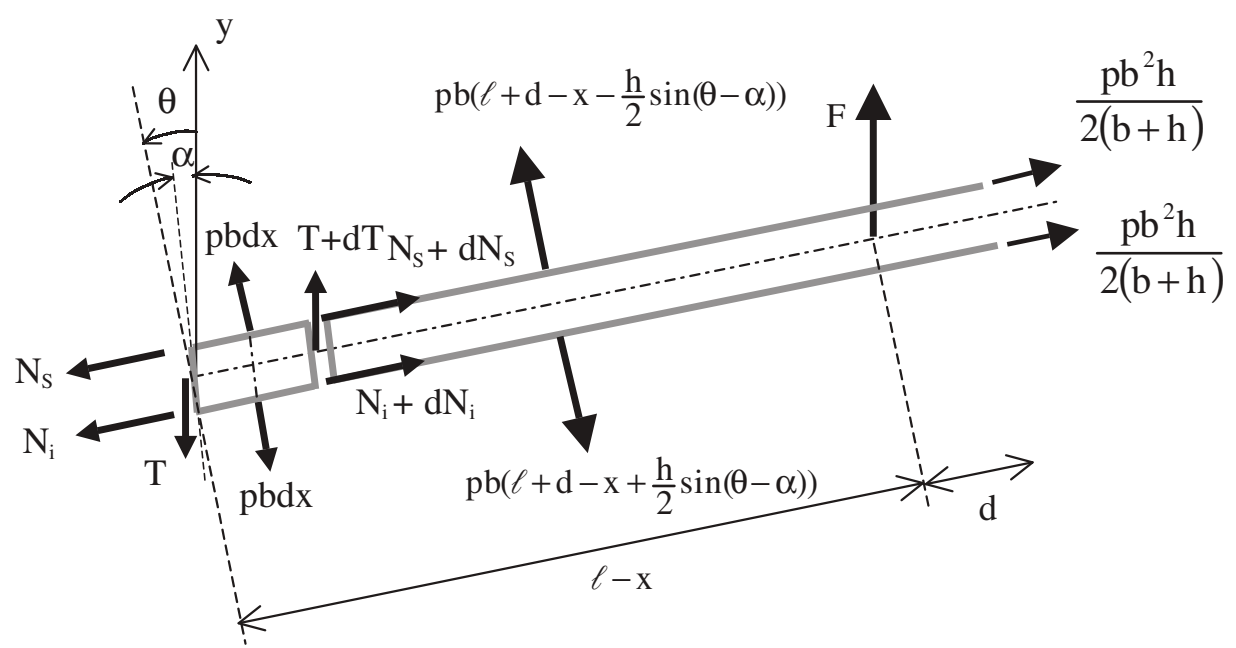

Figure 1. Local and global equilibrium of the panel.

construct an inflatable beam finite element able to give the values of the displacement field for hyperstatic inflatable beams.

\section{MECHANICS OF INFLATABLE BEAMS}

The mechanics of inflatable beams will be developed for inflatable panels. These structures are prototypes constructed by Tissavel Inc. They are made of two parallel-coated woven fabrics connected by yarns. Their behaviour depends on the inflation pressure $p$ that leads the fabrics and the yarns to be prestressed and then to support local compression loads. Experimental and analytical results on the behaviour of these structures can be found in Reference [1].

Let us consider a cantilever panel submitted to a concentrated force $F$. The width and height are named $b, h$ and $\ell$ is the length of the beam. The mechanical strength of the panel is obtained by use of its equilibrium equations, the constitutive law of the fabrics, and kinematics assumptions on its deformation pattern.

\subsection{Equilibrium equations}

Let us come back on the main results of [1]. Equilibrium equations are written for an element in its deformed position to take into account the geometrical stiffness and the following forces. The initial position refers to the inflated beam, without any load. The panel is supposed to present large straight parts. We must use a Timoshenko's beam theory because the straight section of the panel does not stay orthogonal to the neutral fibre (see Figure 5. In Reference [1]). $\alpha$ Denotes the rotation of the straight section and $\theta$ denotes the rotation of the neutral fibre. The pressure effects are supposed to be replaced by forces normally applied to the membranes, because they are following forces. $N_{i}$ and $N_{s}$ denote the resultant stresses, respectively, in the lower and upper membrane; $T$ is the shear stress. All the theory is based upon the hypothesis that the structure's behaviour depends mainly on the values of $N_{i}$ and $N_{s}$. Figure 1 presents a sheet of the pressurized panel. 
The local equilibrium equations allows to write that $N_{i}+N_{S}$ and that the shear stress $T$ is constant. The global equilibrium equations are given for a cantilever beam:

$$
\begin{aligned}
N_{s}+N_{i} & =\frac{p b h^{2}}{b+h} \\
T & =F-p b h(\theta-\alpha) \\
F(\ell-x)+\frac{h}{2}\left(N_{S}-N_{i}\right) & =0
\end{aligned}
$$

And the stresses in the membranes are:

$$
\begin{aligned}
& N_{i}(x)=\frac{p b^{2} h}{2(b+h)}-\frac{F}{h}(\ell-x) \\
& N_{s}(x)=\frac{p b^{2} h}{2(b+h)}+\frac{F}{h}(\ell-x)
\end{aligned}
$$

\subsection{Deflections}

If $P$ is a point of the neutral fibre and if $Q_{i}$ and $Q_{s}$ are two points of the lower and upper membranes, their displacements are obtained by the following relations:

$$
\mathbf{u}(\mathbf{P})=u(x) \mathbf{e}_{x}+v(x) \mathbf{e}_{y}, \quad \mathbf{u}(Q)=\mathbf{u}(P)+\boldsymbol{\Omega} \wedge \mathbf{P Q} \quad \text { with } \boldsymbol{\Omega}=\alpha \mathbf{e}_{z}
$$

The horizontal displacement $u(x)$ and the deflection $v(x)$ are only functions of $x$. The local strains $\varepsilon_{i}(x)$ and $\varepsilon_{s}(x)$ in the two membranes are therefore:

$$
\varepsilon_{i}(x)=u_{, x}+\frac{h}{2} \alpha_{, x} \quad \varepsilon_{s}(x)=u_{, x}-\frac{h}{2} \alpha_{, x}
$$

Resultant stresses are obtained from the constitutive law of the fabric and are given by

$$
N_{i}(x)=\frac{p b^{2} h}{2(b+h)}+\frac{E^{*} b h}{2} \alpha_{, x} \quad \text { and } \quad N_{s}(x)=\frac{p b^{2} h}{2(b+h)}-\frac{E^{*} b h}{2} \alpha_{, x}
$$

where $E^{*}$ is the membrane modulus (product of the Young modulus $E$ by the thickness $e$ of the fabric). $E^{*}$ is obtained from uniaxial traction experiment on a sample fabric. In fact, fabrics are orthotropic materials and the membrane moduli are different in warp and weft directions. In this beam formulation, the warp direction is mainly concerned, and we will suppose that an isotropic constitutive law can be used to give a 'beam answer' to the engineering problem. Moreover, the viscous properties of the fabrics are not taken into account in our theory, hence all the measurements have been done after the creep has stopped.

The comparison between formulas (4), (5) and (8) gives:

$$
\frac{\mathrm{d} \alpha}{\mathrm{d} x}=\frac{2 F}{E^{*} b h^{2}}(\ell-x)
$$

By using Equation (2), and assuming that for these inflatable panels, the shear stress can be neglected with respect to the influence of the normal stress [1], we can write:

$$
\frac{\mathrm{d} v}{\mathrm{~d} x}=\frac{F}{p b h}+\alpha
$$


The boundary conditions at the clamped end give the closed form of the deflection, where $I^{*}$ is equal to the second moment of area divided by the thickness:

$$
v(x)=\frac{F}{p b h} x+\frac{2 F}{E^{*} b h^{2}}\left(\ell \frac{x^{2}}{2}-\frac{x^{3}}{6}\right)=\frac{F}{p b h} x+\frac{F}{E^{*} I^{*}}\left(\ell \frac{x^{2}}{2}-\frac{x^{3}}{6}\right)
$$

which is nothing but the sum between the tight yarn and the beam deflections. In an other word, the compliance of the inflatable panel is the sum of the yarn compliance and of the beam compliance.

\section{CONSTRUCTION OF THE INFLATABLE FINITE ELEMENT}

Let us consider an inflatable beam and denote by $V$ and $F$ the total displacement and load vectors:

$$
\begin{aligned}
& V^{\mathrm{T}}=\left[\begin{array}{llll}
v_{1} & \alpha_{1} & v_{2} & \alpha_{2}
\end{array}\right] \\
& F^{\mathrm{T}}=\left[\begin{array}{llll}
F_{1} & \Gamma_{1} & F_{2} & \Gamma_{2}
\end{array}\right]
\end{aligned}
$$

The definition of nodal unknowns is usual: $v_{i}$ and $\alpha_{i}$ denote displacement and rotation at node $\mathrm{i}$, and $F_{i}$ and $\Gamma_{i}$ denote load and torque at the same node.

When this element is a cantilever inflatable beam submitted to a load and a torque at node 2 , its compliance matrix $\xi$ is simply obtained by adding the usual matrices of beam and yarn:

$$
\left[\begin{array}{c}
v_{2} \\
\alpha_{2}
\end{array}\right]=\xi\left[\begin{array}{c}
F_{2} \\
\Gamma_{2}
\end{array}\right]=\left[\begin{array}{cc}
\frac{\ell^{3}}{3 E^{*} I^{*}}+\frac{p \ell}{S} & \frac{\ell^{2}}{2 E^{*} I^{*}} \\
\frac{\ell^{2}}{2 E^{*} I^{*}} & \frac{\ell}{E^{*} I^{*}}
\end{array}\right]\left[\begin{array}{c}
F_{2} \\
\Gamma_{2}
\end{array}\right]
$$

where $S$ is the area of the section of the extremity $(S=p b h)$.

The global equilibrium equations are:

$$
\left[\begin{array}{l}
F_{1} \\
\Gamma_{1}
\end{array}\right]=\left[\begin{array}{cc}
-1 & 0 \\
-1 & -\ell \\
1 & 0 \\
0 & 1
\end{array}\right]\left[\begin{array}{l}
F_{2} \\
\Gamma_{2}
\end{array}\right]=B\left[\begin{array}{l}
F_{2} \\
\Gamma_{2}
\end{array}\right]
$$

The usual theory of the equilibrium finite element method shows that the stiffness matrix $K$ of the free finite displacement element is obtained from the stiffness matrix of the reduced isostatic finite element $K_{\mathrm{r}}$ by using the following equations:

$$
K=B K_{\mathrm{r}} B^{\mathrm{T}}
$$

where the reduced matrix $K_{\mathrm{r}}$ is the inverse of the compliance matrix $\xi$ :

$$
K_{\mathrm{r}}=\xi^{-1}
$$




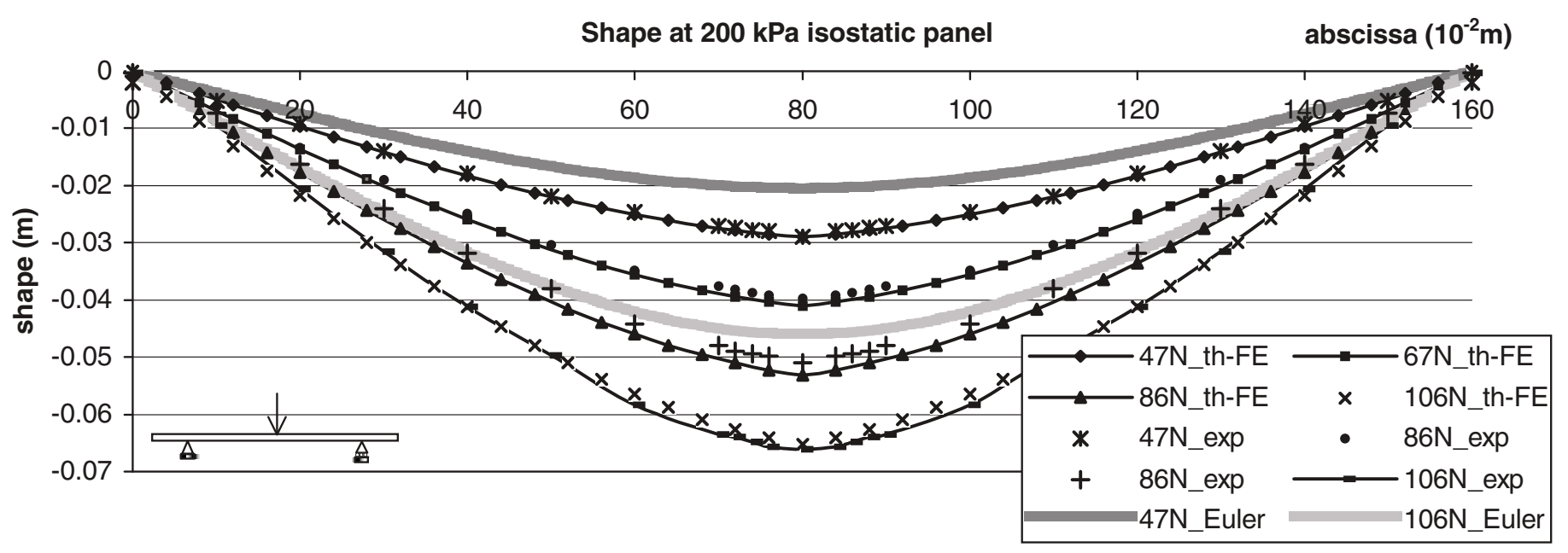

Figure 2. Deflection of the panel-isostatic case.

The free stiffness matrix of the inflatable fabric beam element is therefore:

$$
K=\frac{12 E^{* 2} I^{* 2} p S}{\ell^{2}\left(12 E^{*} I^{*}+p S \ell^{2}\right)}\left[\begin{array}{cccc}
\frac{\ell}{E^{*} I^{*}} & \frac{\ell^{2}}{2 E^{*} I^{*}} & -\frac{\ell}{E^{*} I^{*}} & \frac{\ell^{2}}{2 E^{*} I^{*}} \\
\frac{\ell^{2}}{2 E^{*} I^{*}} & \frac{\ell^{3}}{3 E^{*} I^{*}}+\frac{\ell}{p S} & -\frac{\ell^{2}}{2 E^{*} I^{*}} & \frac{\ell^{3}}{6 E^{*} I^{*}}-\frac{\ell}{p S} \\
-\frac{\ell}{E^{*} I^{*}} & -\frac{\ell^{2}}{2 E^{*} I^{*}} & \frac{\ell}{E^{*} I^{*}} & -\frac{\ell^{2}}{2 E^{*} I^{*}} \\
\frac{\ell^{2}}{2 E^{*} I^{*}} & \frac{\ell^{3}}{6 E^{*} I^{*}}-\frac{\ell}{p S} & -\frac{\ell^{2}}{2 E^{*} I^{*}} & \frac{\ell^{3}}{3 E^{*} I^{*}}+\frac{\ell}{p S}
\end{array}\right]
$$

One can see that the pressure appears in the stiffness matrix.

\section{COMPARISONS BETWEEN EXPERIMENTAL AND FINITE ELEMENT RESULTS}

Figure 2 shows comparisons between finite element modelling (FE) and experimental results (exp.) for a simply supported panel pressurized at $200 \mathrm{kPa}(b=0.2 \mathrm{~m}, h=0.055 \mathrm{~m}, \ell=1.6 \mathrm{~m})$. The usual beam solution (Euler assumptions) is presented too for 47 and $106 \mathrm{~N}$ and is inaccurate. The average value of $E^{*}$ is $650000 \mathrm{~Pa} \mathrm{~m}$. Deflections are obtained for loads varying from 47 to $106 \mathrm{~N}$, just lower than the wrinkling load.

The main advantage of a beam finite element is to be used for solving problems of hyperstatic beams. A panel clamped at one end and simply supported at the other end has been tested up to its wrinkling load. Figure 3 shows one of the experiments made on this panel. Comparisons between experimental and finite element results is shown in Figure 4. Even if the section of the panel is vertical at the clamped end, the angle of the neutral fibre is not equal to zero, in accordance with Timoshenko's beam theory. One can see that the results obtained with the inflatable beam finite element are close to the experimental ones. Moreover, values of the resultant stresses, according to formula (8), give the wrinkling load of the panel. 


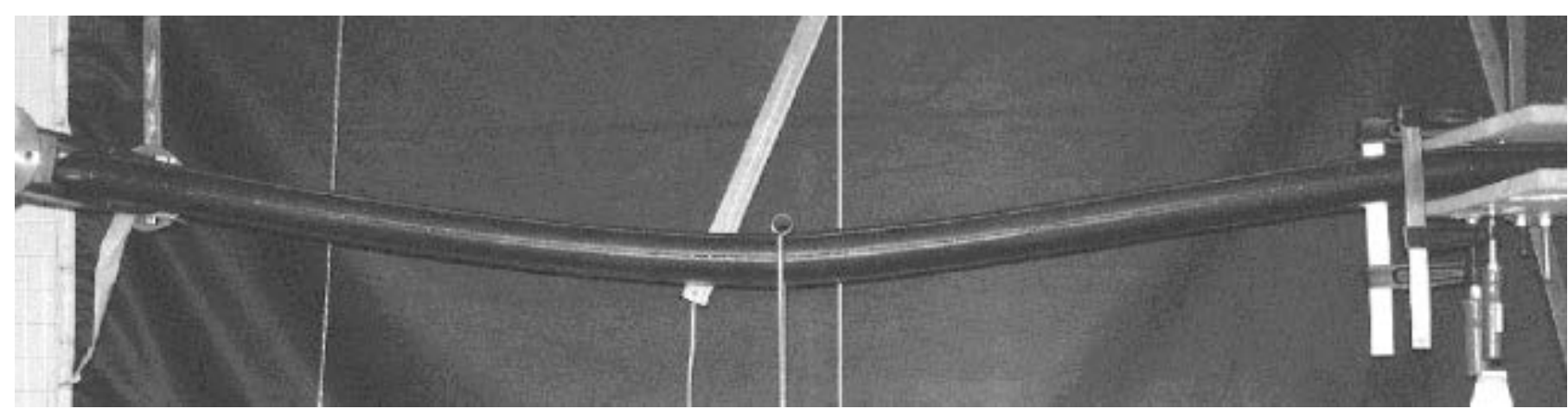

Figure 3. Experiment on inflatable panel: hyperstatic case.

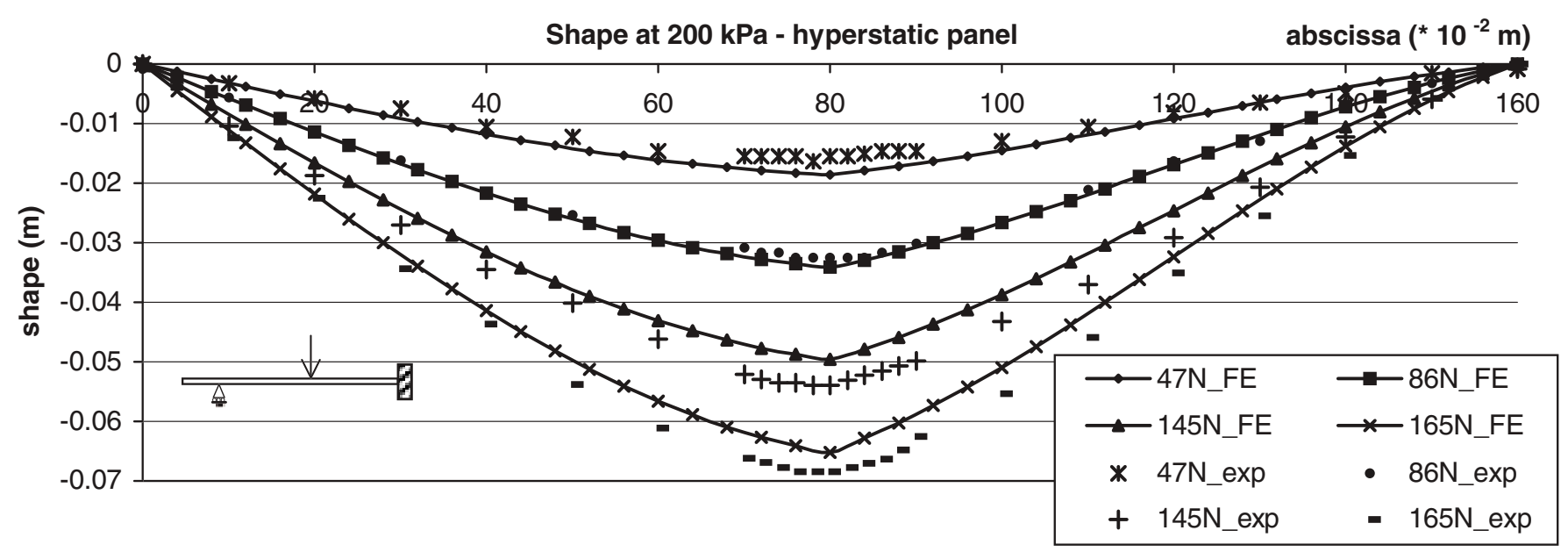

Figure 4. Deflection of the panel-hyperstatic case.

\section{CONCLUSION}

A new finite element devoted to the study of inflated panels has been constructed taking into account the geometrical stiffness and the following forces. The stiffness matrix takes into account the internal pressure of the beam. Comparisons between experimental and numerical results for isostatic and hyperstatic panels prove the accuracy of this theory on the mechanical strength of inflatable beams at high pressure and the efficiency of this inflatable finite element.

\section{REFERENCES}

1. Wielgosz C, Thomas JC. Deflections of inflatable fabric panels at high pressure. Thin-Walled Structures 2002; 40:523-536.

2. Comer RL, Levy S. Deflections of an inflated circular cylindrical cantilever beam. AIAA Journal 1963; 1: $1652-1655$.

3. Main A, Peterson SW, Strauss AM. Load-deflection behaviour of space- based inflatable fabric beams. Journal of Aerospace Engineering 1994; 7:225-238. 